\title{
Social Justice and Community Development: A Multilevel Community Engagement Model to Effectively Work with Families Living in Culturally-Diverse Communities in Pakistan
}

\section{Hassan Raza}

Missouri State University, Springfield, Missouri, United States, drrazahassan84@gmail.com

Follow this and additional works at: https://scholarhub.ui.ac.id/ajce

Part of the Social and Behavioral Sciences Commons

\section{Recommended Citation}

Raza, Hassan (2021). Social Justice and Community Development: A Multilevel Community Engagement Model to Effectively Work with Families Living in Culturally-Diverse Communities in Pakistan. ASEAN Journal of Community Engagement, 5(1), 25-48. Available at: https://doi.org/10.7454/ajce.v5i1.1111

Creative Commons License

(c) (i) ()

This work is licensed under a Creative Commons Attribution-Share Alike 4.0 License.

This Research Article is brought to you for free and open access by the Universitas Indonesia at ASEAN Journal of Community Engagement. It has been accepted for inclusion in ASEAN Journal of Community Engagement. 


\title{
Social Justice and Community Development: A New Multilevel Community Engagement Model to Effectively Work with Families Living in Culturally-Diverse Communities in Pakistan
}

\author{
Hassan Raza ${ }^{1 *}$ \\ Missouri State University, Springfield, Missouri, United States \\ Correspondence email: drrazahassan84@gmail.com
}

Received: November 2, 2020, Accepted: March 21, 2021

\begin{abstract}
The current paper introduces the Multilevel Community Engagement Model (MCEM) to help development agencies effectively work with families living in diverse communities in Pakistan. This model is grounded in family systems theory, participatory action research (PAR), and ecological systems theory. It is also informed by three empirical studies and the author's reflections of his direct observations and experiences based on his work with development agencies. The MCEM uncovers important insights about the complex, dynamic, and reciprocal interactions among different groups of stakeholders at three different engagement levels (i.e., proximal, influential, and holistic). MCEM emphasizes a strong collaboration, effective coordination, and open communication among stakeholders within and between these levels. Development agencies can use and apply MCEM, which may help them adequately understand the needs of families living in diverse communities and address those needs in socially just manners. Additionally, MCEM honors community voice and encourages local knowledge, which may magnify the efforts of stakeholders' groups who are involved in the community development process and situated within/between three different engagement levels and ensure the successful sustainability of development projects in Pakistan. Although, this model is grounded in research, which was carried out in Pakistan, it is intended to be adapted such that it can be transformed and applied in other countries/societies/cultures. The implications and limitations of MCEM are discussed.
\end{abstract}

Keywords: Family systems theory; participatory action research; ecological systems theory; social justice; community engagement.

\section{Introduction}

The current paper presents a Multilevel Community Engagement Model (MCEM). This model is grounded in family systems theory (Smith \& Hamon, 2017), participatory action research (PAR; Herr \& Anderson, 2015), and ecological systems theory (Bronfenbrenner, 1979). It is also informed by empirical research and direct observations of the author (Raza, 2017; 2018; 2020). The Multilevel Community Engagement Model provides a comprehensive framework for development agencies to effectively work with families living in diverse communities in Pakistan. 
Pakistan is a developing country in South Asia, with a population of almost 208 million (National Institute of Population Studies, 2020). Nearly 132 million are living in rural areas whereas 76 million are residing in urban areas of the country (National Institute of Population Studies, 2020). Pakistan is the fifth most populous country of the world (United Nations Department of Economic and Social Affairs, 2019). Pakistan faces many social and economic problems including but not limited to poverty, unemployment, low education levels, gender inequality, high fertility rates, and natural disasters (Pakistan Demographic and Healthy Survey, 2017-18).

The social sector in Pakistan has been experiencing many challenges, which include lack of funding and inadequate coverage for initiatives towards community development. Relevant departments and nongovernment organizations lack sufficient training and resources to work with vulnerable communities. There are also insufficient scientific inquiries and a lack of data to support and develop community level projects (Social Welfare Pakistan Annual Plan, 201516). Consequently, target communities receive insufficient services and information when they need it which negatively impacts community development (Raza, 2020). It is evident that governmental and nongovernmental organizations have been working to bring substantial and positive changes in the lives of diverse communities found in Pakistan (Raza, 2017). The use of data and stakeholders' consultations in implementing development projects can be observed more frequently than in the past (Raza, 2020). Stakeholders refer to participants or a group of people who are involved in a process or an activity for the purpose of creating a greater/valued good (Freeman, 1994). There have been many changes and improvements in terms of the approaches and strategies governmental and nongovernmental organizations utilize to effectively work with diverse communities, the heart of which include a transformation from traditional top-down approaches to more culturally appropriate/responsive bottom-up approaches (McCarthy, 2014). Some of the current projects carried out in Pakistan are more participatory and encourage multisector stakeholders' engagement and participation. For instance, international organizations, such as the United Nations Children's Fund (UNICEF) and the United Nations Development Fund (UNDP) are working with youth (ages between 1424) and encouraging them to develop and share innovative ideas that may help to improve education, employment, and health conditions for women and girls (UNICEF, 2019). Participatory approaches were also utilized in an experimental study, which assessed the impact of community based interventions accompanied with community meetings among community members and the use of mobile phones to discuss school issues and encourage continuous dialogue through text messages to bring improvements in education and schooling. Participants 
included parents, school committee members, and the broader community. The results showed an increase in students' retention from grades $2-4$, teachers' availability, and community interest in education (Asim \& Riaz, 2020).

Despite these improvements, there are some gaps in the existing efforts, which need to be addressed. First, top-down approaches are still actively functioning in the development sector, which can limit community engagement (Pieczka, 2011). Second, the reciprocal nature of relationships between target families and stakeholders' groups is not considered in development programs/projects. Third, the use of a theory driven and empirically grounded framework in community projects/programs is lacking. Given the diversity found in communities throughout Pakistan in the form of strong religious beliefs/practices, economic disparities, views concerning traditional gender norms and stakeholders' groups located at different levels of society, a comprehensive multilevel framework is needed to support the existing efforts that may provide these organizations with a roadmap to address these issues in more appropriate manners.

In order to fulfill the aforementioned gaps, the purpose of the current paper is to present a new Multilevel Community Engagement Model to effectively work with diverse communities in Pakistan. MCEM is grounded in family system theory, participatory action research, and ecological systems theory. MCEM is also informed by the three empirical studies of the author and his direct observations/experiences. MCEM may provide development agencies with a roadmap while facilitating a common language among stakeholders' groups and development organizations that may strengthen their efforts towards community engagement and development, resulting in sustainable outcomes.

\subsection{Family systems theory}

According to family systems theory, families function as a system in which family members are interrelated with each other, such that if one member is affected they influence the whole family system (Smith \& Hamon, 2017). Hence, it is important to examine a family as a single system instead of the sum of its parts. Families establish their boundaries; this determines, what information may or may not be shared outside of the family and who is considered inside or outside of the family (Darling \& Cassidy, 2014). There are also subsystems within the family. These subsystems have their own boundaries and hierarchies (Olson et al., 2019). The hierarchies of these subsystems are determined based on the influence and power of family members, for example a parents' subsystem may be situated at the highest level in the hierarchy of subsystems particularly when they are the economic provider of the family (Smith 
\& Hamon, 2017). Therefore, to better understand and solve family issues through development or family-focused projects, it is imperative to treat the family as a system (Darling \& Cassidy, 2014). For instance, each family member is a unit and is interrelated with other family members which comprise the family system.

In the context of Pakistan, many development projects focus on programs for women or children, such as reproductive health, early childhood care and education. The participation of male family member(s) in these projects is lacking. Pakistani society is male dominant and a male member (i.e., husband,) of the family is most likely the primary provider and head of household. This male family member will likely have the most influence in running the family system. Consequently, the interventions may not show desired/expected outcomes if only women or children are the focus of the program due to the lack of husband/fathers' involvement. Hence, it is important to use a family systems lens in the development of family focused projects, treating families as a system to adequately engage target families in projects and to understand the needs of the entire family. This may increase the likelihood that their needs will be met in culturally appropriate/responsive and holistic manners (Duncan \& Goddard, 2017).

\subsection{Participatory Action Research}

Participatory Action Research (PAR) is a bottom-up approach, which has been used by researchers/practitioners to work with diverse communities; this approach has proven to be very successful in terms of achieving project sustainability and positive outcomes (Herr \& Anderson, 2015). PAR emphasizes the importance of engaging community people in the decision-making process of community development (Herr, 1999). PAR helps researchers/ practitioners to discover community strengths while acknowledging local knowledge and expertise (Freire, 2000). It allows researchers to carry out a collaborative process of development in which all stakeholders particularly the direct/target beneficiaries (e.g., community members) are actively involved throughout the life cycle of the project (Herr, 1995). This involvement encourages active buy-in and provides added community value placed results (Raza, 2020). Researchers as well as community members both take on the role of learners, co-constructing knowledge and helping each other to discover strengths that prove to be essential for community development and the sustainability of development projects (Herr, 1995).

Past research has revealed sustainable and positive outcomes achieved in community development by researchers who utilized PAR (Gilhooly \& Lee, 2017). PAR offers 
considerable opportunities for community members to utilize local knowledge and expertise, which provides them with a sense of ownership and increases their motivation for compliance by seeking appropriate options to foster success (Herr \& Anderson, 1993). Given the diverse community differences found in local languages, traditions, and practice of local culture throughout Pakistan, it is important for development agencies to use PAR in development projects. The use of PAR allows for the engagement of community stakeholders, including target families, in the decision-making process and throughout the entire trajectory of development projects. This approach may increase the knowledge and skills of all stakeholders involved in the development process while creating project buy-in by community members/families in Pakistan. Consequently, development projects may show more sustainable outcomes.

\subsection{Ecological systems theory}

In this section, the 1978 version of Bronfenbrenner's theory, which he called the ecological model of human development, commonly known as the ecological systems theory, is discussed. According to ecological systems theory, human development takes place due to the interrelationships between the developing person and four interconnected ecological systems (i.e., micro, meso, exo, and macro systems; Bronfenbrenner, 1979). Individuals have direct interactions with others in the microsystem, such as family; the mesosystem connects two or more microsystems, such as work and family, the exosystem indirectly affects individuals, such as media, and public institutions, and the macrosystem refers to individuals' values, beliefs, and ideologies. These ecological systems have reciprocal relationships with each other and with individuals. Individuals can influence these ecological systems as they are active agents in their change and can be influenced by them.

In the past in Pakistan gender roles were more traditionally stringent, whereas in current society roles are becoming more egalitarian in nature (Khurshid, 2015). A societal change can be seen in women's growing participation in the current labor force, and achieving higher educational levels, which was not the case in the past (Pakistan Economic Survey, 2019-20). Education and employment were among the most important factors which played an important role in changing gender roles (Raza et al., 2012b). Consequently, instead of only staying home and caring for their children, women are going out and earning income, which increases their respect in the family and power/influence in their relationship with their husband/partner. As a result, their husband/partner also helps them in their household work and childcare tasks/responsibilities. It is mentionable that the prevalence of traditional norms varies in 
Pakistan and the society is still informed by patriarchal ideology (Raza et al., 2012a). Moreover, individuals/families go through different trajectories (developmental changes) over their life course. Some events are normal and predicted (age specific), whereas others are unpredictable which affect individuals'/family development over time (Smith \& Hamon, 2017). Individuals and families who are at different developmental stages may experience societal changes differently, whereas some individuals/families may experience particular societal changes when they occur while others do not, which may have long lasting effects on their lives (Martin, 2018). As mentioned earlier, in general Pakistani society practices collectivistic culture. However, there are substantial differences among groups in their cultural practices at the local level based on the areas of diversity, such as class, place of residence, caste, and language, thus, there are multiple cultural layers that requires sufficient cultural knowledge and skills to effectively work with diverse communities in Pakistan. Thus, development projects can be implemented at various levels and stakeholders from these levels can be engaged to bring positive, comprehensive, and sustainable changes in the lives of families living in diverse communities in Pakistan.

The Multilevel Community Engagement Model was developed based on family systems theory, participatory action research, and ecological systems theory. MCEM offers a multilevel process to effectively work with diverse communities in Pakistan. In sum, treating a target family as a system, using participatory action research approach to involve target families in the decision making process, and engaging stakeholders at various ecological levels, may provide a comprehensive framework for development agencies that leads to higher levels of community engagement and development.

\section{Methods}

The method of this research is a critical review of three empirical studies conducted by the author as well as his direct observations/experiences of working with development agencies in Pakistan. In this section, the author explains how he used his past studies and theoretical lens along with his continuous reflection of direct observations and experiences of working with development agencies to develop MCEM. Table 1 illustrates the process of MCEM development. 
Table 1. Process of MCEM Development

\begin{tabular}{|c|c|c|c|c|}
\hline Author's Studies & Issues and Gaps & $\begin{array}{l}\text { Theoretical Len and } \\
\text { Reflections }\end{array}$ & Thoughts and Answers & $\begin{array}{c}\text { Multilevel Community } \\
\text { Engagement Model (MCEM) }\end{array}$ \\
\hline $\begin{array}{l}\text { Raza, H. (2020). The role of reflexivity in } \\
\text { participatory action research to empower } \\
\text { culturally diverse communities in Pakistan. } \\
\text { Journal of Rural and Community Development, } \\
\text { 15, 71-88. } \\
\text { https://journals.brandonu.ca/jrcd/article/view/1671 } \\
\text { Raza, H. (2018). Participatory action research: } \\
\text { Working beyond disaster towards prevention. } \\
\text { Natural Hazards, } 91 \text { 117-131. doi. } \\
\text { 10.1007/s11069-017-3114-x } \\
\text { Raza, H. (2017). Using a mixed method approach } \\
\text { to discuss the intersectionalities of class, } \\
\text { education, and gender in natural disasters for rural } \\
\text { vulnerable communities in Pakistan. Journal of } \\
\text { Rural and Community Development, 12, 128-148. } \\
\text { http://journals.brandonu.ca/jrcd/issue/view/37 }\end{array}$ & $\begin{array}{l}\text { The intersections of class, } \\
\text { gender, education, and } \\
\text { disability made some } \\
\text { community } \\
\text { families/groups more } \\
\text { vulnerable than the others. } \\
\text { Community members } \\
\text { showed a lack of } \\
\text { knowledge and awareness } \\
\text { about public policies and } \\
\text { programs that are } \\
\text { relevant/responsible to } \\
\text { provide them with } \\
\text { assistance in natural } \\
\text { disasters. } \\
\text { The collaboration, } \\
\text { coordination, and } \\
\text { communication among } \\
\text { stakeholders' groups } \\
\text { including target } \\
\text { communities was } \\
\text { insufficient. } \\
\text { The representation and } \\
\text { recognition of community } \\
\text { voices in the decision- } \\
\text { making process of } \\
\text { community-based } \\
\text { programs/projects were } \\
\text { lacking. } \\
\text { Despite all these } \\
\text { challenges, community } \\
\text { people/families have } \\
\text { wisdom, local knowledge, } \\
\text { and expertise for which } \\
\text { they should be recognized. }\end{array}$ & $\begin{array}{ll}\text { - } & \text { Family Systems } \\
\text { Theory } \\
\text { - } \quad \text { Participatory Action } \\
\text { Research } \\
\text { - } \quad \text { Ecological Systems } \\
\text { Theory } \\
\text { - Author' reflections of } \\
\text { his direct observation } \\
\text { and experiences of } \\
\text { working with } \\
\text { development } \\
\text { agencies. }\end{array}$ & $\begin{array}{l}\text { All family members } \\
\text { should be involved in } \\
\text { community initiatives/ } \\
\text { programs regardless of } \\
\text { age and gender. } \\
\text { Power hierarchies should } \\
\text { be minimized between } \\
\text { practitioners/researchers } \\
\text { and community members } \\
\text { in community-based } \\
\text { programs/projects so that } \\
\text { all groups can co- } \\
\text { construct knowledge and } \\
\text { learn from each other in } \\
\text { the process of community } \\
\text { development. } \\
\text { Family diversity and } \\
\text { community context } \\
\text { should be acknowledged } \\
\text { within and between } \\
\text { stakeholders' groups. } \\
\text { Learning process should } \\
\text { be inclusive, fair, and } \\
\text { equitable such that local } \\
\text { knowledge and expertise } \\
\text { can be recognized and } \\
\text { utilized for community } \\
\text { development. } \\
\text { A strong collaboration, } \\
\text { consistent coordination, } \\
\text { and open communication } \\
\text { is needed among all } \\
\text { involved and relevant } \\
\text { stakeholders including } \\
\text { target families within and } \\
\text { between different } \\
\text { engagement levels. }\end{array}$ & $\begin{array}{l}\text { - Stakeholders' groups } \\
\text { including target families } \\
\text { that are located at three } \\
\text { different engagement } \\
\text { levels (i.e., proximal, } \\
\text { influential, and holistic) } \\
\text { have reciprocal } \\
\text { relationships with each } \\
\text { other within and between } \\
\text { these engagement levels. } \\
\text { These three engagement } \\
\text { levels also have reciprocal } \\
\text { relationships with each } \\
\text { other. } \\
\text { The dynamics of each } \\
\text { stakeholders' group and } \\
\text { their reciprocal } \\
\text { relationship with each } \\
\text { other within and between } \\
\text { three engagement levels } \\
\text { can be influenced by } \\
\text { sociocultural and historical } \\
\text { factors. } \\
\text { Some stakeholders' groups } \\
\text { are more proximal than the } \\
\text { others, whereas some } \\
\text { stakeholders' groups are } \\
\text { more influential than the } \\
\text { others. } \\
\text { The influence of } \\
\text { stakeholders' groups on } \\
\text { each other within and } \\
\text { between the three } \\
\text { engagement levels may } \\
\text { change due to sociocultural } \\
\text { and historical factors. }\end{array}$ \\
\hline
\end{tabular}




\subsection{The Author's studies}

Raza (2017) conducted a study, which utilized a mixed methods approach to analyze a secondary data set that consisted of a sample size of 200 households and six focus groups in the Muzaffargarh District, which is located in the southern Punjab province. The author used logistic regression to analyze quantitative data and thematic analysis to analyze qualitative data. He also used Intersectionality theory as a theoretical framework to examine and explain the results of this study. The data revealed that intersections of class, gender, education, and disability increased the risk of facing an agricultural loss for one group of families following natural disasters compared to their counterparts.

In a follow-up study conducted in 2018, the author took an in-depth approach to further analyze the qualitative data of the same survey (Raza, 2018). He used Participatory Action Research as a framework to examine the data and highlight the strengths and vulnerabilities of community members. One of the important themes to emerge from the data was "Sources of Vulnerabilities" in which community members showed a lack of knowledge and awareness about public policies and programs that were relevant and responsible to provide assistance in natural disasters. Community members not only had a lack of information about these policies and programs, they also did not have any knowledge or information about the local relevant departments or agencies, which were responsible to assist these communities by carrying out adequate measures in case of natural disasters.

Despite all of these challenges, these communities have wisdom, local knowledge, and expertise. They used their local knowledge as a tool to deal with natural disasters. For instance, some experienced members of these communities went to the riverside and observed its movement, based on which they could make a flood prediction. These experts then communicated with other community members and informed them about their prediction. Consequently, community people carried out preventative actions, such as making safety bags, which are made of plastic or cloth used to keep their important documents, such as land ownership documents. Some community members found information about the relevant agencies and reached out to them for information about natural disasters and asking for assistance. This evidence illuminates that although community people do not have appropriate resources to deal with natural disasters, they are committed and willing to handle them by using their local knowledge and expertise.

A separate study conducted by Raza (2020) used Participatory Action Research as a framework to explain his work and experiences with seven community-based organizations in a two-month project of training and evaluation in the Muzaffargarh District. The training 
included survey research, qualitative interviewing, proposal writing, stakeholders' analysis and collaboration, data collection, report writing, and seeking funding opportunities. In this study, he described how he carried out a process of transformation from traditional top-down approaches to non-traditional bottom-up approaches. He highlighted community strengths, local knowledge, and wisdom which he magnified by providing members with additional/external resources in terms of knowledge and skills. He emphasized the importance of building community trust to increase motivation among community members to ensure their engagement and participation to work for achieving project goals. The one size fits all model does not usually work in such situations as each community is unique and diverse with a distinctive context and different needs, which require adequate consideration from researchers/practitioners who work with them. Hence, strong collaboration, effective coordination, and open communication among stakeholders, including target communities, is crucial for the success and sustainability of development projects that results is community engagement and development.

\subsection{The Author's reflection}

The purpose of writing this reflection is not to criticize the work that development agencies are doing in Pakistan and around the world but to provide a context for this paper, which may be essential, to help development agencies effectively work in culturally diverse communities in Pakistan and elsewhere.

While working with local, national, and international agencies, most of them primarily focused on community development, I observed that appropriate collaboration and active engagement among stakeholders' groups and the participation of target families in the decisionmaking process were lacking. Often target families had no knowledge of project objectives and potential outcomes. Target families had no prior experience with donor agency staff who were responsible for designing and supervising projects in which target families were participating. These target families were also not provided with adequate opportunities to participate in developing any implementation and assessment strategies/plans with the local/implementing agency. Community people were participating in events, workshops, or mobilization sessions because they were invited to attend these sessions. These events/activities followed more traditional approaches than participatory. There were power hierarchies between those who were funding/implementing the project and target communities. Funding agencies had very few visits to the locations where their projects were implemented. The staff from donor agencies usually communicated by emails and telephone, progress was monitored through biweekly or monthly 
reports. Target communities were not aware of project goals, objectives, and sometimes they had no knowledge about the staff of donor agencies and their offices because they were mostly interacting with local/implementing agencies personnel. There was also a lack of frequent collaboration between government, implementing, and donor agencies. The use and engagement of other relevant stakeholders' groups who were located at local, provincial, or national levels were minimal. Most of the project campaigns utilized print media, whereas the use of electronic and social media was lacking. Community people were to perform predetermined activities, which were aligned with the donor or implementing agency's goals/objectives. It was less likely that implementing agencies consulted target communities while writing proposals for grants. The use of assessments, scientific inquiry, and data were also lacking in proposing community projects. The coordination between relevant nongovernment agencies were lacking; instead, there was likely a competition among them. There was also a lack of use of a common understood vocabulary or framework that could have enhanced the communication among stakeholders' groups and provide a consistency across different projects among them.

It is mentionable that development agencies including donor and local/implementing agencies and their staff were making substantial efforts, but their efforts were limited due to the rules and policies which were governing them. I also observed a steady change from traditional top-down approaches to participatory bottom-up approaches in development projects. Community people showed commitment, dedication, wisdom, motivation, and agency to bring changes in their lives and the lives of their communities.

\subsection{Process of MCEM development}

After identifying common gaps and issues across three studies, the author used family systems theory, participatory action research, and ecological systems theory to find answers and guide further suggestions, which are the following. First, all family members should be involved in community initiatives regardless of age and gender. Power hierarchies should be minimized between practitioners and community members in community-based programs/projects. Community context and cultural diversity among families should be acknowledged within and between stakeholder groups. Learning processes should be inclusive, fair, and equitable such that local knowledge and expertise can be recognized and utilized for community development. A strong collaboration, consistent coordination, and open communication is needed within and between different engagement levels among all involved and relevant stakeholders including target families. This process was also accompanied by the author's continuous reflection and 
examination of his own biases and positionality while reflecting how that might have potentially influenced the overall research process. Consequently, the author developed and introduced a new Multilevel Community Engagement Model.

\section{Results and discussion}

\subsection{Multilevel Community Engagement Model (MCEM)}

Figure 1 shows the Multilevel Community Engagement Model, which is grounded in family systems theory, participatory action research, ecological systems theory, empirical research, and direct observations and experiences of the author. There are three engagement levels of the Multilevel Community Engagement Model. The first level (which is called the proximal level) includes "Families" that refers to target families, and "Community" which refers to the implementing agency, social activists, local government departments, health centers, nongovernment organizations working in the same area and other relevant agencies. The second level (which is called the influential level) includes "Donor Agencies" and "Media \& Government Institutions." Donor agencies refer to the private or public funding agencies. Media refers to electronic, print, and social media. Electronic media includes television, radio, internet, or any electronic source of information. Print media includes newspaper, magazine, brushers or any printed source of information, and social media, such as Facebook, Twitter, and Instagram, whereas Government Institutions refer to state/provincial or federal government departments and agencies, those which do not usually or frequently have direct interactions with target families, but they may have indirect influence on them and the projects targeting these families. The third level includes "Diversity" that refers to race, class, gender, ethnicity, education, sexual orientation, disability, place of residence, marital status, family structure, religion, immigrant status, or any other area of diversity that may shape the experiences of these families and their interactions with other stakeholders' groups within and between these three engagement levels. "Culture" refers to the cultural beliefs, values, ideologies, traditional, customs, and any other cultural aspects/practices that distinguish one group from the other group in society. According to MCEM, groups at each of these three engagement levels have reciprocal relationships with each other within and between these levels. In addition, these three levels also have reciprocal relationships with each other. 


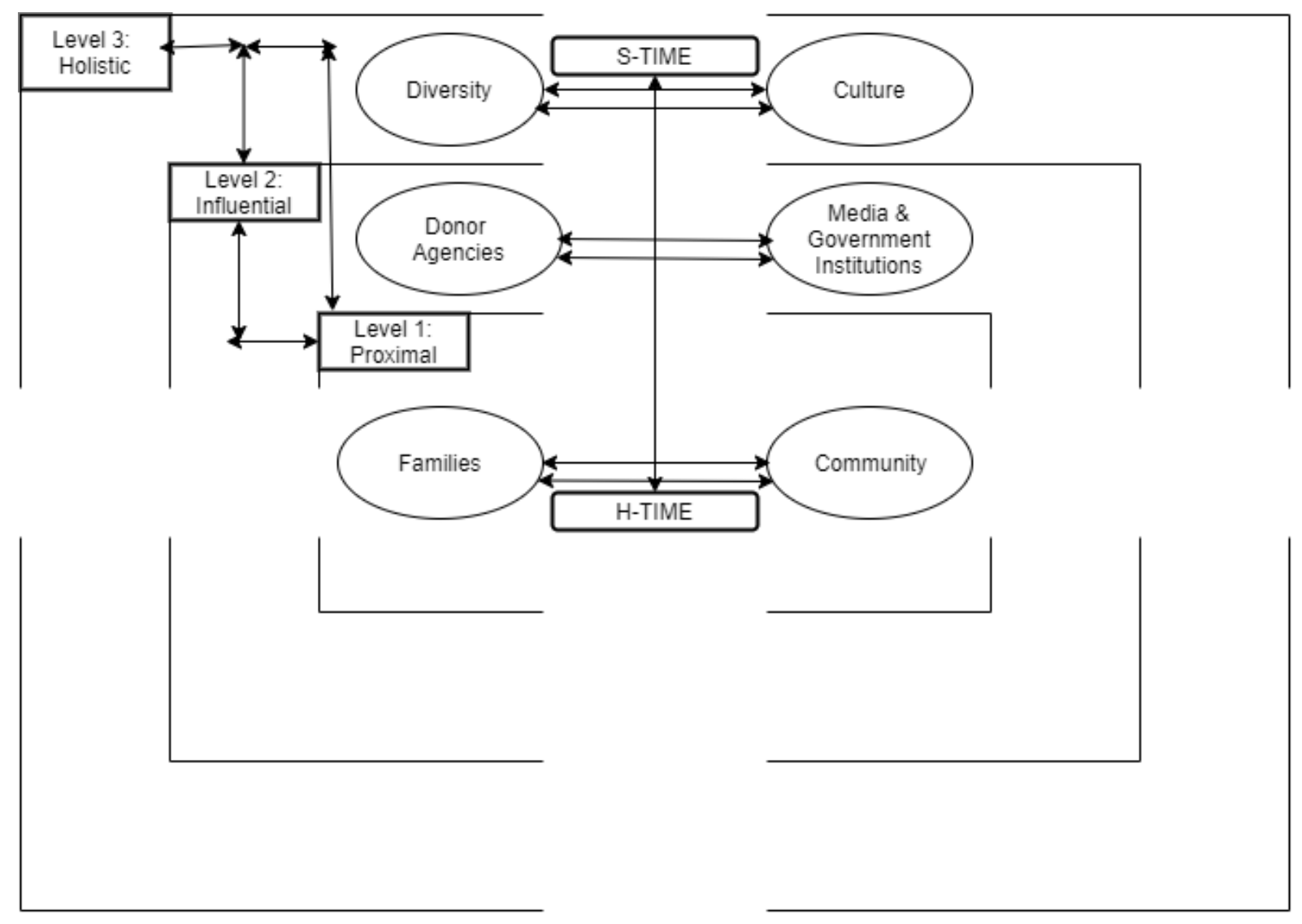

Note: S-TIME $=$ Sociocultural time $;$ H-TIME $=$ Historical Time

Figure 1. Multilevel Community Engagement Model (MCEM)

As mentioned earlier, MCEM is introduced in this paper, and it has the potential to evolve when tested and applied through research and practice. Further testing, validation, and application of MCEM may help uncover insightful information about the systems and structures that are either already exit or need to be in place to strengthen the collaboration between stakeholders' groups within and between these levels and allow these groups to work at different engagement levels to find out where their communities might fit.

The last and the most essential component of the Multilevel Community Engagement Model is "Time." Time refers to the sociocultural and historical changes occurring in society over time as it can potentially affect all groups included in the model and vice versa. At the first level (i.e., the proximal level), families in Pakistan have been changing over time. For instance, although society is still informed by patriarchal norms/systems, gender roles are changing for women. Women are receiving higher levels of education and they are outperforming men in educational achievements (Khurshid, 2017). In the past, women were married at an early age, which limited their opportunities to attain high educational levels and secure high paying employment. Traditionally after getting married, a woman's role was to stay home, care and 
nurture their children, while performing household labor. Currently, women are focusing on their educational goals and attaining higher education. Women are entering into nontraditional occupations, such as business, marketing, management, engineering, and taking leadership roles (Raza et al., 2012b). However, as a reinforcement of the model it is worth noting that this change varies across social classes.

Women with higher levels of education who can afford to go to better schools are more likely to have better professional and communication skills, which are essential for leadership positions thereby they are more likely to occupy leadership roles compared those women who belong to low socioeconomic status. Hence, inequalities still exist across social classes, although changes have been occurring. The socialization process that parents carry out to bring up their children has also been changing as parents are recognizing the importance of education for their daughters' future. Hence, families are changing the society and sociocultural changes that have been happening in society are influencing families to change and adapt. This situation varies due to many factors, such as place of residence, access to media, parents' education, income level, number, and gender of siblings.

Additionally, changes have been occurring in local development agencies which are working with families. For instance, educated and skilled staff are working in these agencies, thus more emphasis is given on staff trainings and professional development activities. In addition, collaboration, and engagement between implementing agencies, target communities, and potential stakeholders at the community level are increasing. Hence, changes have been happening among these groups which are situated at the local level and have direct interactions with families with which they work (Raza, 2020).

At the second level (influential), donor agencies are increasingly engaging local agency personnel in decision-making processes instead of directing them to predesigned project goals and objectives. Although the engagement of local agencies in the decision making process, designing project goals and objectives is increasing, there are still top-down approaches and hierarchies that can be observed between donor and local agencies that needs to be shifted for effective project implementation, empower local/target communities, and ensure sustainability of development projects (Raza, 2020). Donor agencies are increasingly emphasizing accountability, program evaluation, and evidence-based practices. Personnel from donor agencies are acknowledging the importance of acquiring cultural competence to effectively work with local agencies and target communities for successful implementation and positive outcomes of development projects. Therefore, there are changes occurring in policies, procedures, and strategies of donor agencies over time. 
In addition, due to globalization, media in Pakistan has become quite advanced. Information is more reliable and frequent. However, media quality varies from place to place due to issues, such as access and quality of sources of information. For example, television and mobile phones are more prevalent in urban areas. According to a national survey, $86.4 \%$ of the urban households have a television and $48.1 \%$ of the rural households own a television. In addition, $97.5 \%$ of the urban households own a mobile phone and, $91.6 \%$ of the rural households have a mobile phone (PDHS, 2017-18). People have more access to internet services, such as websites and emails to communicate with others and look for reliable and relevant information. Thus, people are more informed about changes in the economy, public policies, and government programs. Additionally, they are expressing their opinions in terms of their likes and dislikes regarding public policies and programs. In response the government is adapting to changes at the local, national, and international levels. The federal government has transferred power to the provincial and district government to effectively allocate the resources and adequately address the needs of local families (United States Institute of Peace, 2018). Hence, changes have been happening in media and government in Pakistan over time.

At the third level (holistic), as discussed, includes areas of diversity, such as religion, class, gender, and place of residence. These have strong influence on the lives of individuals and families in Pakistan. For instance, people are becoming more informed about religion and educating themselves about religion through reputable sources. Formal institutions are offering degrees and certificates in religious education, with the government supervising these institutions, such as International Islamic University, Islamabad, Pakistan. People are more tolerant and liberal in terms of religion differences compared to the past. Hence, changes are happening in terms of how people learn, use, and approach religion in Pakistan.

The distribution of income has been very unequal, economic disparities exist and are explicit among families of different classes. Due to economic downfall, over population, issues surrounding law and order (e.g., crime rates), there are high levels of unemployment and underemployment in the country with people struggling to fulfill basic needs. Children and women are the most vulnerable groups who are affected due to unfavorable changes and inequalities happening in society. Consequently, maternal, and infant mortality rates are quite high in Pakistan compared to other countries in the region (PDHS, 2017-18). On the other hand, women have more access to education and employment. Women are working hard towards achieving their goals, pursing their careers, securing better futures for their children, and gaining equality in intimate relationships, whereas institutions are offering increasing educational and employment opportunities for women. 
Consequently, over time, gender disparities are decreasing, and women are becoming more active, functional, and empowered in Pakistani society. Additionally, the government is building more formal schools and offering more education opportunities in rural areas in terms of school-based education. Health care facilities are being established in rural and remote areas where doctors and health workers are appointed to provide health and reproductive services to rural families. Additionally, due to advancements in technology and transportation, rural families can communicate with their loved ones who reside outside of town or city for education and employment and travel to meet with them. Hence, changes have been happening and families living in underdeveloped areas are gaining more access to education, health, and employment over time.

Similarly, cultural changes are also happening among families due to education, media, and globalization. As discussed earlier, gender roles are changing, and women are actively participating in social, political, and economic activities instead of staying home. Parents are encouraging their daughters to travel to other cities and countries for better educational and occupational opportunities. A steady transition can be seen in cultural socialization in terms of gender from traditional to non-traditional norms that girls experience in their childhood. There are now special seats in parliament allocated exclusively for women. Women have played an important role in policymaking and change in the recent past. Women are running nongovernment organizations, working on electronic media, perusing their careers, performing leadership roles, and working as social activists. Consequently, women are playing an important role in bringing substantial changes in the lives of families and at the societal level. Although cultural practices, such as son preference still exist in society, there have been important cultural changes, such as the elimination of dowry also observed within Pakistani society (The Nation, 2020).

The above discussion implies that "Time" played an integral role in bringing changes and shaping families' experiences in society. Hence, it is crucial for development agencies to understand the sociocultural and historical contexts of target families/communities to working with them effectively, understanding their needs appropriately, achieving project outcome positively, and ensuring sustainability of their project adequately. Since Pakistani society is more diverse, this model uncovers dynamic and complex interactions within and between groups of stakeholders and their relationships with society to appropriately develop, implement, and evaluate development projects at the local level. The importance of societal/historical context is ever developing. For example, due to COVID-19, the dynamics of society, economics, and social interactions have been considerably changed. Consequently, the 
interactions among stakeholders' groups with each other and the target communities/families within and between three engagement levels also have been changed. Therefore, such a comprehensive and multilevel model is much needed in the current situation to adequately understand the unique needs of diverse families and fulfil those needs in timely and appropriate manners.

The model illustrates an open area at all four sides of each level, which emphasizes the importance of strong collaboration, effective coordination, and open communication among all groups of stakeholders at all three engagement levels. As discussed earlier, since these levels have a reciprocal relationship with each other, stakeholders' groups at every level not only affect each other within each level but also the others at a different level. Hence, the collaboration, coordination, and communication among stakeholders within and between these levels would be extremely useful for the success and sustainability of development projects. Although MCEM is based on the research conducted in Pakistan, it is intended to be much broader and can applied in other countries/societies/cultures allowing the focus to be shifted to other areas of diversity, such as race, class, ethnicity, sexual orientation, disability, immigration status and language as needed to be culturally relevant. As stated earlier, this model is at its initial stage. It has the potential to evolve as it will be used and applied in research and practice in the future.

\subsection{Discussion}

The purpose of this article is to offer a comprehensive model to development agencies that suggests effective engagement among stakeholders within and between different engagement levels who are involved in projects for community development. To fulfill this purpose, the author presents a new Multilevel Community Engagement Model (MCEM) that uncovers complex and dynamic interactions among potential stakeholders within and between three different engagement levels (level 1: proximal; level 2: influential; level 3: holistic). MCEM stressed strong collaboration, effective coordination, and open communication among stakeholders that may result in community empowerment and development.

The author provided a critical examination of his own studies (Raza, 2017; 2018; 2020), and used family systems theory, participatory action research, and ecological systems theory along with the reflections of his direct observations and experiences of working with development agencies in the process of MCEM development. Based on a critical examination of the author's studies, it was found that there were gaps at different engagement levels among relevant stakeholders including target families. Community members had local knowledge, but they 
lacked awareness and information about relevant departments/agencies, which could have provided them with external resources. Often, they neither had knowledge about the relevant public policies or programs at the provincial or federal levels nor did they have information about the relevant local district level departments/agencies. Community members might be active in obtaining information, but they did not have frequent access to sources of information (e.g., internet, television, and mobile) to fulfill their needs.

Second, community people had the wisdom, and they were ready to work as active agents to change the lives of their people. They showed commitment to their work and utilized local knowledge as much as they could for the well-being of their community/family. They were the experts who knew appropriate solutions of their community problems. Each individual stakeholders' group had unique strengths and abilities that could be utilized and strengthened through an external assistance to bring changes in their communities. They were willing and committed to acquire external knowledge and skills that could foster their local knowledge and expertise to make efforts towards community development.

This illustrates a discrepancy/gap in communicating and understanding community needs at both ends. For instance, community people have the courage, and they want assistance in their preventative actions, particularly in natural disasters, but they normally only receive post disaster help and assistance. Even though they carry out their preventative actions themselves to move to safer places, the immediate community resources do not support them (e.g., they do not have transportation and the cost of transportation substantially increases in natural disasters) this could be managed by the responsible relevant governmental or nongovernmental departments/agencies.

This evidence also implies that there are gaps among stakeholders' groups that situate and function at different engagement levels in terms of collaboration, coordination, and communication. Some stakeholders, such as local governmental departments and implementing agencies have direct influences on these families/communities, whereas other stakeholders, such as media, donor agencies, and federal government/provincial governments and their policies have indirect influences on them. In addition, culture and areas of diversity, such as religion, class, gender, and education also play an important role in such situations as some groups receive unfair privilege and advantages over others. This may promote and perpetuate inequalities among families living in diverse communities. Hence, there is an essential need for the Multilevel Community Engagement Model to address these discrepancies/gaps and provide development agencies with a comprehensive framework to 
effectively work with diverse families/communities that may adequately fulfill community needs and ensure the success and sustainability of development projects.

MCEM also addresses the issues of diversity and social justice in community engagement and development. For instance, the Family Systems approach allows development agencies to invite and engage all family members actively in the project and treat a family as a whole system instead of the sum of its different parts (Smith \& Hamon, 2017). In Pakistan, there are disparities based on gender. Men are more likely to be the head of households who make most of the important decisions. They are more likely to participate in social, economic, and political activities. When development agencies and relevant stakeholders' groups, including target families, carry out appropriate actions to engage all family members (men and women) in projects, their programs/interventions may eliminate the inequalities between men and women, which may ensure inclusion of all family members regardless of gender, age, and disability. Thus, promoting social justice at the family level. This in turn directly addresses the issue of diversity.

In addition, men are less likely to participate in reproductive and childcare activities in Pakistan. For instance, women usually visit family health centers alone or they take an older family member, such as their mother-in-law or sister-in-law with them to discuss reproductive health issues, such as the use of contraception etc. Even when family health workers conduct home visits to discuss reproductive matters, men are less likely to directly engage in such conversations but have the power to influence women's reproductive decisions, such as the use of contraception and fertility. Thus, when development agencies use the family systems perspective and make considerable efforts to engage all family members in their projects, their interventions will be more effective, which may result in more positive and sustainable outcomes.

PAR honors community voice and invites a range of expertise and problem solving throughout the decision-making process (Herr, 2017). This process brings vulnerable community members into the category of an expert along with the development personnel, which seeks to eliminate inequalities and encourages everyone who is involved in the process to respect, learn, and utilize each other's knowledge and skills regardless of race, class, and gender. This collaborative process of recognition and engagement of target communities make their local knowledge and expertise visible to others. Helping local communities to identify and frame the issues they face rather than just intervening when problems have already occurred and strongly exists within communities. Hence, PAR helps development agencies to develop socially just collaborations with communities while seeking to create effective 
interventions that do not hold vulnerable communities in endless cycles. Such a collaborative process that is comprised of socially just reciprocal interactions among people who belong from a variety of groups and possess a range of expertise can be more effective and powerful, which may result in sustainable outcomes of development projects.

Ecological systems theory may help development programs to consider the influence of multi-systems on their projects and encourage them to collaborate with stakeholders who are situated at different ecological systems (Bronfenbrenner, 1979). Since the effect from each level is reciprocal, the process of participation and engagement may be more interactive, consistent, and continuous, which in turn may help magnify each party's efforts. For example, the engagement of relevant local government departments can make policies more suitable for the project design, implementation, and evaluation while also providing an appropriate environment/infrastructure, which is supportive to that project. Consequently, the results can be more powerful and effective. Similarly, media has a strong influence on people's thinking, behaviors, and perceptions. If development agencies can engage media to advocate and mobilize families concerning their projects, it may make a positive impact on the target families. Additionally, respecting, understanding, and becoming more culturally competent may also make the interventions more effective and the outcome might be more successful and sustainable.

Additionally, the consideration of historical changes in project planning, implementation, and evaluation processes may also offer opportunities for development workers to engage target families/communities and ensure their active participation. Research shows that motivation encourages community members to actively engage in the projects and show commitment (Raza, 2020). When researchers/practitioners show community people an appropriate understanding of their culture, traditions, and customs, and give the community ownership of their work, community members are encouraged to show and utilize their local knowledge and expertise in development projects (Raza, 2020). Therefore, before jumping into the project design and implementation, a substantial amount of time and effort is needed to understand sociocultural and historical aspects of target communities, which pays off in the later stages of project cycle.

Therefore, the Multilevel Community Engagement Model, which is grounded in family systems theory, participatory action research, and ecological systems theory, addresses the areas of diversity and social justice in community engagement and development. At the first level (i.e., the proximal level), the family systems and participatory approaches help development agencies to focus more on families and move from individuals' efforts to 
community efforts, which may magnify these efforts and energy for change and sustainability. Since groups at each engagement level have reciprocal relationships with and influence on each other, the actions and energy at the proximal level may push the other levels (i.e., the influential and holistic) much harder for change, which then may respond reciprocally with the effect that may turn into more substantial, consistent, continuous, dynamic interactions and an evolving change process over time. Hence, MCEM increases the opportunities or possibilities to push for more than just doing typical arrangements in society because the push and demands come from the bottom-up (i.e., the proximal level) that reciprocally interact with other groups situated at other engagement levels (i.e., the influential and holistic). Consequently, the needs of families living in diverse and vulnerable communities would be recognized and addressed.

To bring programs to another level in Pakistan, the implementation of MCEM would be helpful. Hence, MCEM offers a comprehensive framework to empower vulnerable families by using a family systems approach to work with families as a whole instead of the sum of different parts, encourages collaboration by inviting families into problem solving and decision-making processes, and emphasizes open communication among potential stakeholders within and between different levels. MCEM is much needed in diverse societies, such as Pakistan, where families are culturally diverse and their needs are unique, especially as the interplay between society and families are becoming more dynamic and complex. As mentioned earlier, MCEM is intended to be much broader such that it can be applied to other diverse societies, like the United States where the diversity among families exist, family structures are becoming more complex and dynamic, and the issues of diversity, inclusion, and justice are growing and becoming more visible. While the foundation of MCEM is an anchor, additional work is required towards the transferability and applicability of Multilevel Community Engagement Model to other societies/countries and/or communities.

\section{Conclusion}

The current paper offers some important implications, which are discussed in this section. First, MCEM is a unique contribution in the scholarly literature of community engagement and development. Second, MCEM highlights the dynamic and complex interplay among potential stakeholders' groups including target families and provides development agencies, researchers, and practitioners with a comprehensive framework to effectively work with diverse communities. Third, MCEM is grounded in scientific research and theories, which increases the validity of this model. Fourth, MCEM may help development agencies and researchers/practitioners to acknowledge and understand unique community contexts, which 
may increase the likelihood that their projects may better address community needs. Fifth, MCEM may assist development agencies and researchers/practitioners to achieve project sustainability and positive outcomes and result in community engagement and development. Finally, MCEM is broad enough that it can be applied and transformed in other countries/societies/cultures and at the same time it is narrow to a degree that it can be empirically adapted, measured, and tested.

Although, the current paper makes a unique contribution in the scholarly literature of community engagement and development, and provides important guidelines to its audience, it contains some limitations. First, the Multilevel Community Engagement Model is at the early stage of its development and introduced for the first time in this paper. As researchers and practitioners utilize it in various settings in the future, it may potentially evolve and adapt over time to meet specific community/cultural needs. Second, although, the author used his past studies, theoretical lens, reflections of his direct observations and experiences of working with development agencies to ground this model, additional research is needed through which this model can be tested for validity and reliability. Third, the author primarily conducted his research in Pakistan, hence, additional research is needed to use and apply MCEM in other countries/cultures/societies in future. Fourth, stakeholders' groups need to identify and learn about each other's relevance and areas of expertise, which may take time, energy, and efforts. Finally, there needs to be a contextual shift, allowing for more inclusivity in what is considered expertise.

\section{Declaration of Conflicting Interest}

There is no conflicting of interest for this manuscript.

\section{Short Biography}

\section{Muhammad Hassan Raza}

Dr. Raza completed his Ph.D. in Family Studies from Montclair State University, New Jersey, United States, and is a Certified Family Life Educator. He taught at Montclair State University as an adjunct faculty for one year. He also taught at Miami University, Oxford, Ohio, United States as a Visiting Professor for one year. He currently works as an Assistant Professor at Missouri State University, Springfield, Missouri. Dr. Raza uses quantitative, qualitative, mixed methods, and action research methodologies in his research. He has experience of working with national and international organizations on research and development in Pakistan. 
Assistant Professor of Child and Family Development, Department of Childhood Education and Family Studies, Missouri State University, Springfield, United States

Research Interest: Family, Work, and Community

Dr. Raza has developed and introduced the Multilevel Community Engagement Model to improve stakeholders' engagement including families in community programs/projects to achieve positive outcomes and project sustainability. Dr. Raza has been working on developing Family Diversity Theory, which may help to understand and explain diverse family experiences in society.

\section{References}

Asim, S., \& Riaz, A. (2020). Community engagement in schools evidence from a field experiment in Pakistan. Policy Research Working Paper, Education Global Practice, World Bank Group, 9280, 1-73. http://hdl.handle.net/10986/33941

Bronfenbrenner, U. (1979). The ecology of human development: Experiments in nature and design. Harvard University Press.

Bronfenbrenner, U. (1978). The social role of the child in ecological perspective. Zeitschrift fur Soziologie, 7, 4-20.

Darling, C. A., \& Cassidy, D. (2014). Family life education. Working with families across the lifespan (3rd ed.). Waveland Press.

Duncan, S. F., \& Goddard, H. W. (2017). Family life education: Principles and practices for effective outreach (3rd ed.). Sage Publications.

Freire, P. (2000). Pedagogy of the oppressed (1st ed.). Bloomsbury Academic.

Freeman, R. E. (1994). The politics of stakeholder theory: Some future directions. Business Ethics Quarterly, 4, 409-421. https://www.jstor.org/stable/3857340

Gilhooly, D., \& Lee, E. (2017). The Karen resettlement story: A participatory action research project on refugee educational experiences in the United States. Action Research, 15, 132-160. https://doi.org/10.1177\%2F1476750315625338

Government of Pakistan, Finance Division (2019-20). Pakistan economic survey. https://www.finance.gov.pk

Herr, K. (1995). Action research as empowering practice. Journal of Progressive Human Services, 6, 45-58. https://doi.org/10.1300/J059v06n02_04

Herr, K. (1999). Unearthing the unspeakable: When teacher research and political agendas collide. Language Arts, 77, 10-15. https://www.jstor.org/stable/41483020 
Herr, K., \& Anderson, G. L. (1993). Oral history for student empowerment: Capturing students' inner voices. International Journal of Qualitative Studies in Education, 6, 185-196. https://doi.org/10.1080/0951839930060301

Herr, K., \& Anderson, G. L. (2015). The action research dissertation: A guide for students and faculty (2nd ed.). Sage Publications.

Herr, K. (2017). Insiders doing PAR with youth in their schools: Negotiating professional boundaries and healing justice. International Journal of Qualitative Studies in Education, 30, 450-463. https://doi.org/10.1080/09518398.2017.1303213

Khurshid, A. (2017). Does education empower women? The regulated empowerment of parhi likhi women in Pakistan. Anthropology \& Education Quarterly, 48, 252-268. https://doi-org.proxy.lib.miamioh.edu/10.1111/aeq.12198

Khurshid, A. (2015). Islamic traditions of modernity: Gender, class, and Islam in a transnational women's education project. Gender \& Society, 29(1), 98-121. https://doi.org.proxy.lib.miamioh.edu/10.1177/0891243214549193

Martin, T. F. (2018). Family development theory 30 years later. Journal of Family Theory \& Review, 10, 49-69. https://doi.org/10.1111/jftr.12237

McCarthy, J. F. (2014). Using community led development approaches to address vulnerability after disaster: Caught in a sad romance. Global Environmental Change, 27, 144-155. https://doi.org/10.1016/j.gloenvcha.2014.05.004

National Institute of Population Studies (2017-18). Pakistan demographic and health survey. Islamabad, Pakistan. http://nips.org.pk/

National Institute of Population Studies (2020). News and updates. http://nips.org.pk/

Olson, D. H., Defrain, J., \& Skogrand, L. (2019). Marriages and families: Intimacy, diversity, and strengths (9th ed.). McGraw-Hill.

Pieczka, M. (2011). Public relations as dialogic expertise? Journal of Communication Management, 15, 108-124. https://doi.org/10.1108/13632541111126346

Raza, H. (2020). The role of reflexivity in participatory action research to empower culturally diverse communities in Pakistan. Journal of Rural and Community Development, 15, 71-88. https://journals.brandonu.ca/jrcd/article/view/1671

Raza, H. (2018). Participatory action research: Working beyond disaster towards prevention. Natural Hazards, 91, 117-131. https://doi.org/10.1007/s11069-017-3114-X 
Raza, H. (2017). Using a mixed method approach to discuss the intersectionalities of class, education, and gender in natural disasters for rural vulnerable communities in Pakistan. Journal of Rural and Community Development, 12, 128-148.

https://journals.brandonu.ca/jrcd/article/view/1338

Raza, H., Sheraz, A., \& Zafar, R. (2012a). Effect of Islamic perception on family planning practices. International Journal of Sustainable Development, 5, 85-96.

http://www.ssrn.com/link/OIDA-Intl-Journal-Sustainable-Dev.html

Raza, H., Wasim, B., Ahmad, F., Raza, Z., \& Khan, N. (2012b). Impacts of family planning programmes on fertility in Pakistan. International Journal of Sustainable Development, 5 , 97-114. http://www.ssrn.com/link/OIDA-Intl-Journal-Sustainable-Dev.html

Smith, S. R., \& Hamon, R. R. (2017). Exploring family theories (4th ed.). Oxford University Press.

Social Welfare Pakistan. (2015-16). Annual plan 2015-16. https://www.pc.gov.pk/

The Nation (2020). Pakistani govt. officially bans dowry now. https://nation.com.pk/

United Nations Department of Economic and Social Affairs (2019). World population prospects 2019. https://population.un.org/wpp/

United Nations Children's Fund Pakistan (2019). Research and reports, generation unlimited. https://www.unicef.org/pakistan/what-we-do

United States Institute of Peace (2018). Devolution of power in Pakistan. https://www.usip.org/ 